\title{
SPINAL CORD ARTERIOVENOUS MALFORMATION
}

\section{A pediatric presentation}

\author{
Paulo José Lorenzoni, Rosana Herminia Scola, Cláudia Suemi Kamoi Kay, \\ Eustáquio de Queiroz, Juliana Cardoso, Moacir Pereira Leite Neto, \\ Karen Pansardi Grisotto, César Vinícius Grande, Isac Bruck, Lineu César Werneck
}

Spinal vascular malformations in child are rare and still under-diagnosed entities that typically lead to progressive spinal cord symptoms and myelopathy if not properly treated'. This malformation can be differentiated into congenital (arteriovenous malformations and cavernomas) or acquired (dural arteriovenous fistulae) forms ${ }^{1}$. Spinal cord arteriovenous malformations (SCAVM) comprise a complex and heterogeneous group of lesions with a number of subtypes that have distinct clinical presentations, anatomic features and natural histories ${ }^{2,3}$. While there are important differences between subtypes, the majority of patients with SCAVM present first clinical manifestations only in adolescence or adulthood ${ }^{2}$.

We describe the characteristics on child with SCAVM and show the possible treatment of this disease on childhood because only few cases have been published.

\section{CASE}

A 4-year-old girl presented sudden onset of lumbar and lower limbs pain, weakness in right lower limb, difficulty walking, constipation and urinary retention. Her parents denied previous similar episodes. She was born at term and was the first child of non-consanguineous parents and the only affected case in the family. The psychomotor development was normal.

Physical examination did not reveal any abnormalities. Neurological examination showed hypotonia in lower limbs (right more than left); muscle strength grade 3 (MRC scale) in the right lower limb and grade 5 in the bilateral upper and left lower limbs; absent right patellar reflex; bilateral Babinski sign; decreased pain, pinprick and light touch sensibility in the right lower limb; and abnormal joint position sense in the right lower limb.

The symptoms and signs were thought to be consistent with spinal cord abnormality, and the investigation showed a cerebrospinal fluid with 5 leukocytes $/ \mathrm{mm}^{3}, 140$ erythrocytes $/ \mathrm{mm}^{3}$, glucose $55 \mathrm{mg} / \mathrm{dl}$ and protein $25.7 \mathrm{mg} / \mathrm{dl}$; needle electromyography and sensory nerve conduction study were normal, but motor nerve conduction study demonstrated absent F-wave in right peroneal nerve; magnetic resonance imaging (MRI) revealed high signal on T1-weighted images and hypointense signal on T2weighted images in area of the T11-T12 spinal cord with concomitant swelling of the T11-L1 cord (Fig 1); and selective spinal angiography demonstrated a small arteriovenous fistula with posterior aneurysmatic formation on T11-T12 spine cord area which was fed by the anterior spinal artery arising from the right $12^{\text {th }}$ and left $9^{\text {th }}$ intercostal arteries (Fig 2A and 2B).

After this initial investigation the patient was submitted to management of the SCAVM. Surgery was performed with clipping of the supplies arteries resulting complete obliteration of the fistula on postoperative spinal angiography (Fig 2C). Followup shows that her symptoms and neurological status improved after surgery.

All studies were done following informed consent of parents.

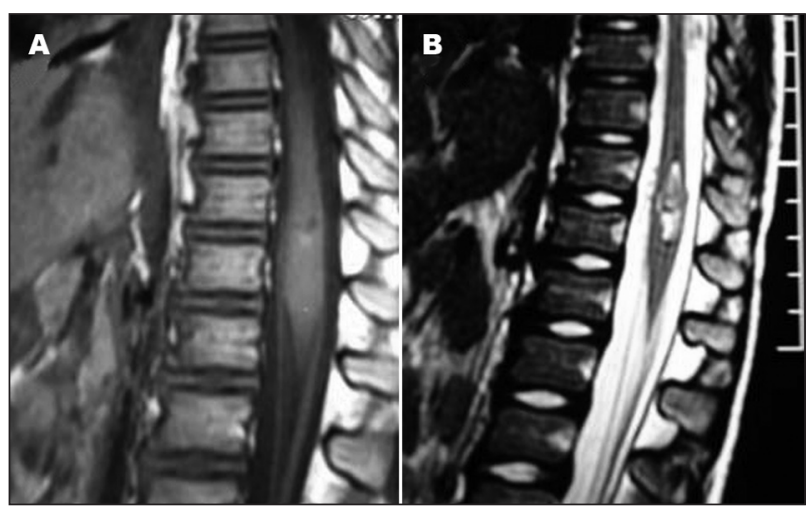

Fig 1. [A] Sagittal T1-weighted MRI shows the main arteriovenous shunt located in the thoracic spine (T11-T12). [B] Sagittal T2-weighted MRI reveals swelling due to spinal cord venous congestion between T11-L1 levels.

\section{MALFORMAÇÃO ARTERIOVENOSA MEDULAR: APRESENTAÇÃO PEDIÁTRICA}

Neurology, Neuropediatric and Neurosurgery Services, Hospital de Clínicas da Universidade Federal do Paraná (UFPR), Curitiba PR, Brazil.

Received 20 October 2008, received in final form 13 January 2009. Accepted 7 April 2009.

Dra. Rosana Herminia Scola - Serviço de Doenças Neuromusculares / Hospital de Clínicas da UFPR - Rua General Carneiro 181 / 39 andar - 80060-900 Curitiba PR - Brasil.E-mail: scola@hc.ufpr.br 

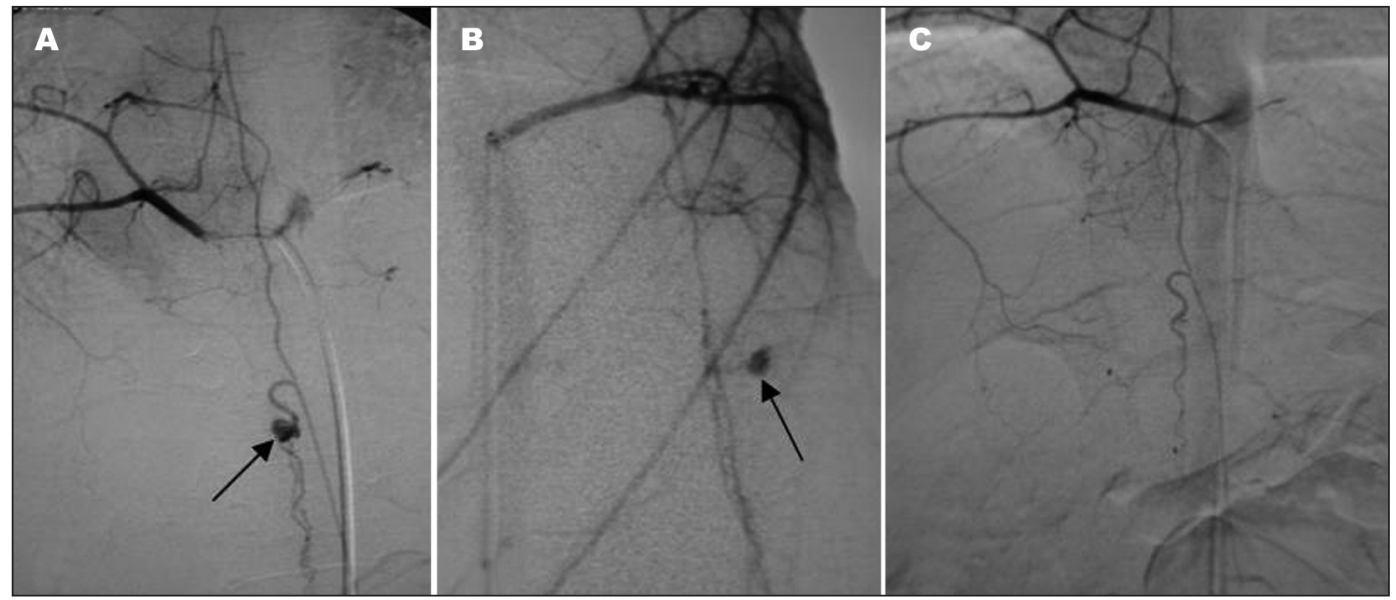

Fig 2. Selective spinal angiography demonstrated a small arteriovenous fistula with posterior aneurysmatic formation (arrows) on T11-T12 spine cord area which was fed by the anterior spinal artery arising from the right $12^{\text {th }}$ and left $9^{\text {th }}$ intercostal arteries [A and B]; with complete obliteration of the fistula on postoperative spinal angiography [C].

\section{DISCUSSION}

SCAVM is a rare congenital vascular malformation of the spinal cord characterized by an arteriovenous shunt, with or without an intervening vascular network, between the feeding artery and the draining vein ${ }^{3-5}$. They are fed by one or many arteries that normally supply the spinal cord $^{5}$. The SCAVM incidence ranging between 20 to $30 \%$ of all spinal vascular shunts, and it were rarely observed during the childhood period ${ }^{1,6}$. SCAVM presentation in the first 2 years of life is exceedingly rare ${ }^{2}$.

Clinical manifestation of the SCAVM depending of the degree of the malformations, but the pathogenesis in spinal cord includes venous congestion and hemorrhage causing myelopathy'. Clinical manifestations can include pain, acute or progressive myelopathy, and radiculopathy ${ }^{7}$. A minority of patients with SCAVM are symptomatic as neonates or infants ${ }^{2}$. In these cases, symptomatology is unspecific if the patient did not present an acute hemorrhage'. Neurological symptoms are attributable to the spinal cord lesion and patients can present weakness or paraplegia associated with sensory deficit or sphincter dysfunction, similar our case ${ }^{2}$. In some cases, SCAVM can be seen genetically associated with hereditary hemorrhagic telangectasia ${ }^{2,4,6}$.

Natural history of neurovascular disease in the pediatric population differs from that of adults in many significant ways, and SCAVM are no exception. Hemorrhagic presentation is more frequent in pediatric population than in adults, except in extremely young children ${ }^{6}$. Importantly, however, neonatal and infant age groups represent a yet more specific group into pediatric population ${ }^{2,6}$. For example, in contrast to report of Rodesch et al which found that $70 \%$ of pediatric patients with SCAVM presented with hemorrhage (vs $45 \%$ of adults), in neonatal and infant cases reported by Cullen et al, hemorrhagic presentation was
$23 \% \%^{2,6,8}$. SCAMV causing venous congestion possibly could be the main pathophysiology feature in neonatal and infant cases $^{2}$. In addition, while nidus SCAVM type predominates in the pediatric population (67\%), the majority of patients have fistulas in the neonatal and infant series ${ }^{2,8}$.

MRI diagnosis is characterized by serpiginous or tubular structures, corresponding to large draining veins $s^{4}$. The MRI can still show the effect of the vascular malformation in the spinal cord: hemorrhage, congestion, compression and deviation by vessels abnormalities ${ }^{4}$. However, it is difficult to precise the shunt involved (fed, drainage, type and localization) by $\mathrm{MRI}^{4,9}$. Angiography remains the gold standard for analysis of the anatomical, morphological and architectural features necessary for therapeutic decisions in both pediatric and adult populations ${ }^{4}$. When a SCAVM of any type is clinically suspected on the basis of unexplained myelopathy or hemorrhage, angiography should be performed even if prior noninvasive imaging studies were unrevealing?.

They have given rise to a large literature, dealing with different analyses that have oriented patients towards various treatment modalities that range from surgery, embolization or a combination of both ${ }^{3,4,10}$. Experiences suggest that endovascular therapy should be the primary treatment of these lesions in the neonatal and infant population ${ }^{2,46}$. However, fistulous SCAVM with a small caliber of the feeding artery can prohibits catheter placement close to the fistula; therefore, a surgery treatment should be favored, as in our case'. Fistulous SCAVM with dilated feed vessel can be submitted to a surgical management or a super selective catheterization to close the fistula by embolized procedures ${ }^{1-3,10}$. In infants, despite early presentation and severe symptoms, these lesions are frequently amenable to endovascular treatment, often with anatomic cure achieved and with improvement or stabilization of symptoms after partial targeted treatment ${ }^{6}$. A 
partial embolization, to obliterate the nidus in glomerular SCAVM, also can improve the prognosis of the patient ${ }^{1,3}$. In juvenile SCAVM, only those parts of the SCAVM responsible by symptomatology should be treated ${ }^{1,3}$.

Despite the increasing use of endovascular techniques there is a significant role for operative management of these conditions at infancy ${ }^{3,10}$. Therefore, treatment should be individualized and integrated by endovascular and surgical procedures, depending on lesional angioarchitecture and clinical status of the patient ${ }^{7}$.

\section{REFERENCES}

1. Krings T, Mull M, Gilsbach JM, Thron A. Spinal vascular malformations. Eur Radiol 2005;15:267-278.

2. Cullen S, Alvarez H, Rodesch G, Lasjaunias P. Spinal arteriovenous shunts presenting before 2 years of age: analysis of 13 cases. Childs Nerv Syst 2006;22:1103-1110.

3. Ferch RD, Morgan MK, Sears WR. Spinal arteriovenous malformations: a review with case illustrations. J Clin Neurosc 2001;8:299-304.

4. Rodesch G, Lasjaunias P. Spinal cord arteriovenous shunts: from imaging to management. Eur J Radiol 2003;46:221-232.

5. Gueguen B, Merland JJ, Riche MC, Rey A. Vascular malformations of the spinal cord: intrathecal perimedullary arteriovenous fistulas fed by medullary arteries. Neurology 1987;37: 969-979.

6. Cullen S, Krings T, Ozanne A, Alvarez H, Rodesch G, Lasjaunias P. Diagnosis and endovascular treatment of pediatric spinal arteriovenous shunts. Neuroimaging Clin N Am 2007;17:207-221.

7. Kim LJ, Spetzler RF. Classification and surgical management of spinal arteriovenous lesions: arteriovenous fistulae and arteriovenous malformations. Neurosurgery 2006;59:195-201.

8. Rodesch G, Hurth M, Alvarez H, Ducot B, Tadie M, Lasjaunias P. Angio-architecture of spinal cord arteriovenous shunts at presentation. Acta Neurochir 2004;146:217-226.

9. Strom RG, Derdeyn CP, Moran CJ et al. Frequency of spinal arteriovenous malformations in patients with unexplained myelopathy. Neurology 2006;66:928-931.

10. Cho KT, Lee DY, Chung CK, Han MH, Kim HJ. Treatment of spinal cord perimedullary arteriovenous fistula: embolization versus surgery. Neurosurgery 2005;56:232-241. 